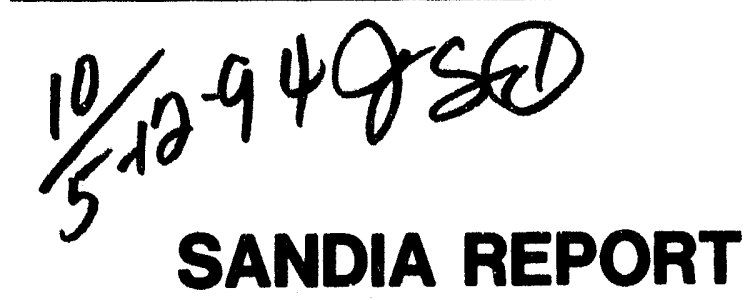

SAND94-0202 - UC-713

Unlimited Release

Printed February 1994

\title{
Development of an Alanine Dosimeter for Gamma Dosimetry in Mixed Environments-Summary of Research
}

David W. Vehar, Patrick J. Griffin

Propered by

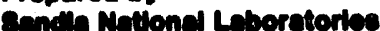

Abueverawe, Now Moxico 87186 and Lwermore, Cellfornla 94680

for the Unitud states Depertinent of Enorgy

under Contreet DE-ACoverulascoo

Approved for public reloace; diatribution is unlimited. 
Ineued by Sandia National Laboratories, operated for the United States Department of Energy by Sandia Corporation.

NOTICE: This report was prepared as an account of work sponsored by an agency of the United States Government. Neither the United States Government nor any agency thereof, nor any of their employees, nor any of their contractors, subcontractors, or their employees, makes any warranty, express or implied, or ascumes any legal liability or responsibility for the accuracy, completeness, or usefulness of any information, apparatus, product, or proceses disclosed, or represents that its use would not infringe privately owned rights. Roference herein to any specific commercial product, process, or sorvice by trade name, trademark, manufacturer, or otherwise, does not nocessarily constitute or imply its endorsement, recommendation, or favoring by the United States Government, any agency thereof or any of their contractors or subcontractors. The views and opinions expresesed herein do not necessarily state or reflect those of the United States Government, any agency thereof or any of their contractors.

Printed in the United States of America. This report has been reproduced directly from the beet available copy.

Available to DOE and DOE contractors from

Office of Scientific and Technical Information

PO Box 62

Oak Ridge, TN 37831

Prices available from (615) 576-8401, FTS 626-8401

Available to the public from

National Technical Information Service

US Dopartment of Commerce

5285 Port Royal Rd

Springfield, VA 22161

NTIS price codes

Printed copy: A03

Microfiche copy: A01 


\title{
Development of an Alanine Dosimeter for Gamma Dosimetry in Mixed Environments -- Summary of Research
}

\author{
David W. Vehar \\ Nuclear Facilities and Diagnostics Department \\ Sandia National Laboratories \\ Albuquerque, NM 87185-1142 \\ Patrick J. Griffin \\ Nuclear Systems Research Department \\ Sandia National Laboratories \\ Albuquerque, NM 87185-1145
}

\begin{abstract}
L- $\alpha$-alanine, a nontoxic polycrystalline amino acid, has been investigated for use in high-precision, high-level absorbed-dose measurements in mixed neutron/photon environments such as research and test reactors. The technique is based on the use of electron paramagnetic resonance spectroscopy to determine the extent of free radical production in a sample exposed to ionizing radiation, and has been successfully used for photon absorbed-dose measurements at levels exceeding $10^{5} \mathrm{~Gy} u^{\circ} \mathrm{i}$ high measurement precision. Application of the technique to mixed environments requires knowledge of the energy-dependent response of the dosimeter for both photons and neutrons. Determination of the dosimeter response to photons is accomplished by irradiations in ${ }^{60} \mathrm{Co}$ and bremsstrahlung sources and by calculations of energy-dependent photon kerma. Neutron response is determined by irradiations in conjunction with $\mathrm{CaF}_{2}: \mathrm{Mn}$ thermoluminescence dosimeters and by calculations of energy-dependent neutron kerma. Several neutron environments are used, including those provided by the Annular Core Research Reactor and Sandia Pulsed Reactor.
\end{abstract}

\section{MASTER}




\section{Acknowledgement}

The authors wish to thank C.V. Holm of the Nuclear Facilities and Diagnostics Department for his valuable assistance in the design and construction of the sample-handling mechanism and automation circuits. 


\section{Contents}

Introduction $\ldots \ldots \ldots \ldots \ldots$

Equipment ........................... 2

Dosimeter Preparation . . . . . . . . . . . . . . . . . . . 2

Equilibration and Dosimeter Packaging. . . . . . . . . . . . . . 3

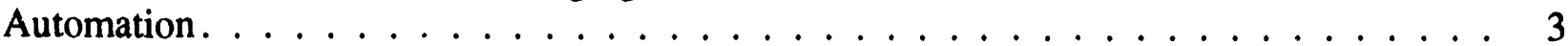

Measurement Parameters . . . . . . . . . . . . . . . . . . . . 4

Typical EPR Spectrum . . . . . . . . . . . . . . . . . . . . . . 4

Gamma Response Curve Characteristics . . . . . . . . . . . . . . . . . 5

Photon Energy Dependence . . . . . . . . . . . . . . . . . . . 6

Neutron Energy Dependence . . . . . . . . . . . . . . . . . . 7

Alternate Materials . . . . . . . . . . . . . . . . . . . . . . 8

Conclusions and Recommendations . . . . . . . . . . . . . . . 8

References ............................ 9

\section{Figures}

Figure 1. Alanine Dosimeter Packets . . . . . . . . . . . . . . . . . . 11

Figure 2. Microwave Cavity and Sample-Changer Mechanism . . . . . . . . . . . . . 11

Figure 3. Alanine EPR Spectrum, Gain=1, FMW=0.5 mT, Dose $=10 \mathrm{kGy}$. . . . . . . . . . 12

Figure 4. Normalized EPR Response, Peak-to-Peak Method . . . . . . . . . . . . . . 12

Figure 5. Normalized EPR Response, Integral Method . . . . . . . . . . . . . . . . . 13

Figure 6. Alanine EPR Spectrum, Gain=1000, FMW=0.05 mT, Dose=10 Gy . . . . . . . . 13

Figure 7. Energy-Dependent Photon Kerma . . . . . . . . . . . . . . . . . . 14

Figure 8. Photon Spectra . . . . . . . . . . . . . . . . . . . . . . . . . . . . . 14

Figure 9. Energy Dependence of Neutron Effectiveness. . . . . . . . . . . . . . . 15

Figure 10. Energy-Dependent Neutron Kerma. . . . . . . . . . . . . . . . . 15

Figure 11. Teflon EPR Spectrum, Gain=100, FMW=0.5 mT, Dose $\sim 600$ Gy . . . . . . . 16

\section{Tables}

Table 1. EPR Measurement Parameters . . . . . . . . . . . . . . . . . . . 4

Table 2. Normalized EPR Response for FMW of $0.5 \mathrm{mT}$ and $0.05 \mathrm{mT} \ldots \ldots$. . . . . . . . 5

Table 3. Ratios of Absorbed Dose for Photons . . . . . . . . . . . . . . . . 6

Table 4. Ratios of Absorbed Dose for Neutrons . . . . . . . . . . . . . . . . . . . 7 
Intentionally Left Blank

- iv - 


\section{Development of an Alanine Dosimeter for \\ Gamma Dosimetry in Mixed Environments \\ - Summary of Research}

\section{Introduction}

L- $\alpha$-alanine, a nontoxic polycrystalline amino acid, has been used in recent years as a dosimeter for high-precision, high-level absorbed-dose measurements in gamma-radiation fields. The technique is based on the use of electron paramagnetic resonance (EPR) spectroscopy to determine the extent of free radical production in a sample exposed to ionizing radiation. It has been successfully used for gamma-ray absorbed-dose measurements at levels exceeding $10^{5} \mathrm{~Gy}$ and with a measurement precision of better than $3.5 \%$ [1]. With carefully controlled conditions, a precision of $1 \%$ can be obtained.

Because of the wide absorbed-dose range and high precision that can be achieved with this method, there is considerable interest in its possible use in radiation-hardness testing of electronics, both in photon and in neutron environments. Photon dosimetry for this application has traditionally been done with $\mathrm{CaF}_{2}: \mathrm{Mn}$ thermoluminescence dosimeters (TLDs), and has therefore been limited to absorbed-dose levels below $2 \times 10^{3} \mathrm{~Gy}$, with a measurement precision of 7 to $10 \%$ [2]. Other applications for which a high-precision dosimeter is needed include facility calibration and absorbed-dose mapping, and characterization of new test configurations. Several radiation facilities at Sandia will benefit directly from the development of a high-precision gamma dosimeter that can be used reliably in neutron environments. The Sandia Pulsed Reactor (SPR-III) and Annular Core Research Reactor (ACRR) facilities are used routinely for testing of electronics devices and components, both for Sandia projects and for other Department of Energy and Department of Defense contractors. Test specifications often call for measurements of both the neutron and photon environments that exceed the range and precision capabilities of available dosimetry systems. Gamma and bremsstrahlung X-ray facilities such as the Gamma Irradiation Facility (GIF) and HERMES-III will also benefit from the high precision and wide range of an alanine dosimetry system.

Before this technique can be used for mixed-radiation fields, it is necessary to characterize the energy-dependent response of the dosimeter for both photons and neutrons. Determination of the dosimeter response to photons is accomplished by irradiations in ${ }^{60} \mathrm{Co}$ and bremsstrahlung Xray sources and by calculations of energy-dependent photon kerma. Neutron response is determined by irradiations in conjunction with traditional dosimeters, supported by calculations of energy-dependent neutron kerma. Several neutron environments are used, including the SPRIII, the ACRR central cavity, and the ACRR Fueled-Ring External Cavity (FREC) [3].

This report summarizes work undertaken as part of a Laboratory Directed Research and Development project for development of an alanine dosimeter for photon dosimetry in mixed environments. It describes development of the basic dosimetry system, characterization of the alanine dosimeter response for a variety of mixed neutron-photon environments, and implementation of the dosimeter system in support of the ACRR and SPR-III reactor facilities and the HERMES-III and GIF photon irradiation facilities. 


\section{Equipment}

The instrument used for the EPR measurements is a JEOL Ltd. JES-RE1X ESR Spectrometer, equipped with a high-sensitivity cylindrical microwave cavity. Other manufacturers also produce EPR spectrometers that would be suitable for this work. The spectrometer magnets have a diameter of $150 \mathrm{~mm}$ and a pole gap of $60 \mathrm{~mm}$, and are capable of generating a magnetic field strength of $650 \mathrm{mT}$. The spectrometer operates at a microwave frequency from 8.8 to 9.6 $\mathrm{GHz}$ (X-band) and power up to $200 \mathrm{~mW}$. Output of the EPR spectrometer is sent to a personal computer where it is digitized, analyzed and stored. An RS-232 interface in the spectrometer enables the computer both to define and to read spectrometer settings. The software used for the data acquisition and analysis is an adaptation of EPRWare [4], which has been modified to allow for automated data acquisition and analysis. A precision synthetic-quartz tube and positioning rod ensure reproducibility in pellet position within the microwave cavity to within $0.02 \mathrm{~mm}$ vertically and $0.1 \mathrm{~mm}$ horizontally. There are no measurable contributions from the quartz fixtures to the measured EPR signals.

\section{Dosimeter Preparation}

Procedures for producing alanine dosimeters have been developed for polyethylene and paraffin binder materials [5]. Uniformity in dosimeter mass better than $1 \%$ is easily achievable using the technical procedures summarized below, but production of large numbers of dosimeters is not yet practical. Work continues on techniques for producing larger quantities of alanine pellets while maintaining required uniformity.

Crystals of L- $\alpha$-alanine (purity $>99.5 \%$ ) are ground using a ball mill, and sieved to particle sizes smaller than 100 microns. This helps ensure random orientation of the crystals in the pressed pellets. In the case of polyethylene binder, the resulting powder is mixed with a binder of polyethylene and stearic acid (both smaller than 100-micron particle size), in the ratio of $80 \%$ by weight of alanine, $19 \%$ by weight of polyethylene, and $1 \%$ by weight of stearic acid. Cylindrical pellets are formed by pressing $100 \mathrm{mg}$ of the mixture in a hand tableting press, with a resulting pellet diameter of $4.5 \mathrm{~mm}$ and height of $5.2 \mathrm{~mm}$. The pellets are sorted by mass to ensure uniformity to within $\pm 1 \mathrm{mg}$. Hardening of the pellets is done by annealing in a Pyrex dish at $130^{\circ} \mathrm{C}$ for 30 minutes, allowing the annealing oven to cool slowly to $85^{\circ} \mathrm{C}$ and holding for 5 minutes, and finally removing the pellets and allowing them to cool at room temperature. The pellets are inspected for flakes or chips, and any unsatisfactory pellets are discarded. In the case of paraffin binder, the mix is $80 \%$ by weight of alanine powder and $20 \%$ by weight of paraffin, and the annealing is performed at $100^{\circ} \mathrm{C}$. The remainder of the procedure is unchanged.

No observable differences could be found in dosimeter response between the polyethylene- and paraffin-based pellets. This was expected, because the elemental composition is virtually identical for the two materials. Differences exist in mechanical properties of the pellets because of the lower melting temperature of the paraffin. The paraffin is softer and more difficult to grind, and results in a pellet that is more susceptible to chipping. Contamination of the sample handling assembly is therefore also more likely. As a result, the use of paraffin as a binder material was discontinued. 


\section{Equilibration and Dosimeter Packaging}

In order to properly measure absorbed dose, a dosimeter must be surrounded by a layer of appropriate material to ensure electron equilibrium [6]. The material chosen and the necessary thickness of that material depend on both the dosimeter composition and the photon spectrum in which the measurement is made. Calculations were performed using the CEPXS/ONELD code [7] to determine the appropriate equilibration for several combinations of dosimeter and photon environments. These calculations are described fully in a separate report [8]. Aluminum is a suitable equilibrator material for $\mathrm{CaF}_{2}: \mathrm{Mn}$ TLDs, while Lucite is a good match for alanine. For the purposes of this study, it was necessary to place both the alanine pellets and the $\mathrm{CaF}_{2}: \mathrm{Mn}$ TLDs in the same package. However, this requires a compromise on the choice of equilibrator. In order to obtain alanine doses with as high accuracy as possible, both the alanine and the TLDs were enclosed in Lucite. Each dosimeter packet, shown in Figure 1, consisted of four alanine pellets and four $\mathrm{CaF}_{2}: \mathrm{Mn}$ TLDs placed in cavities within the Lucite equilibrator. This packaging provides an equilibration thickness of $6 \mathrm{~mm}$, and was used for all environments except the HERMES-III exposures, for which a thickness of $32 \mathrm{~mm}$ was used. Because of the poor match in equivalent atomic number between the Lucite and the $\mathrm{CaF}_{2}: \mathrm{Mn}$ TLD, the TLD is not in electron equilibrium for high-energy photon sources. This is due to enhanced Compton electrons in the equilibrator resulting from photon interactions in the hydrogenous material. Future modifications to the dosimeter package may incorporate an aluminum cover over the TLD.

\section{Automation}

A large number of dosimeters is involved in a systematic investigation of optimum spectrometer settings, data analysis algorithms, and characterization of dosimeters in various radiation fields. Furthermore, there is a significant amount of tedium involved in the measurement of the EPR spectrum for a pellet, including placement of the pellet in the microwave cavity, acquisition of the EPR spectrum, determination of the signal intensity either by measurement of the signal peak amplitude or by integration of the EPR spectrum, and storage of the spectrum and analysis results. This process can take more than two minutes per sample. As a result, some automation of data acquisition and analysis is essential, although full automation is not possible, or even desirable, during the development stages of a new system. Areas that are candidates for automation include sample handling, instrument control, and data analysis.

A sample-changer mechanism, shown in Figure 2, has been constructed for automatic handling of up to 50 pellets and is currently undergoing testing and refinement. Alanine pellets are loaded into a disk into which are machined 50 cylindrical recesses forming a ring near the outer edge of the disk. Each pellet cavity has a small orifice in the bottom to allow a flow of nitrogen to lift the pellet from the recess into a quartz tube that extends through the microwave cavity. To load a pellet into the microwave cavity for measurement, the disk is rotated to place the pellet into position beneath the tube. Upon actuation of a solenoid, nitrogen gas forces the pellet upwards into the tube and against the end of a quartz rod, which defines the pellet position at the center of the microwave cavity. Measurement of the EPR signal can then be made. When the solenoid is deactivated, the pellet drops back into the recess in the disk, and another pellet can be rotated into position. A high-precision stepping motor is used to position the disk. All other samplechanger parts are constructed of non-magnetic materials, i.e., plastics, brass and aluminum. The sample changer operates under computer control, so that coordination with data acquisition, 
analysis and storage is possible. Automation of sample handling is essential for unattended operation, but is practical only for a standard sample configuration, i.e., pellet dimensions and mass. In addition, the pellet design must be consistent with the technique used for sample handling as well as the environments in which the dosimeters will be used. For this reason, the Radiation Metrology Laboratory (RML) has standardized its pellet dimensions without a comprehensive optimization process.

Because the system will be used over a large range of absorbed dose, it is useful to allow the system to determine for itself the most appropriate gain settings for the spectrometer. This is accomplished in several steps. A preliminary scan of an alanine EPR spectrum is done and the signal checked to determine if it lies within an acceptable range, e.g., $5 \%$ to $90 \%$ of full scale. If the signal falls outside that range, the gain is increased or decreased by a factor of 10 , and the preliminary scan is repeated. This process is continued until the signal level is acceptable or until an upper or lower gain limit on the spectrometer is reached. A final scan is then recorded. The EPR spectrometer is capable of a range of sweep times. Preliminary scans can be done with sweep times on the order of a few seconds, but the final scans must be long enough that the magnet can respond adequately without distortion of the EPR signal, i.e., one to two minutes.

Data acquisition and storage were easily automated, because these functions are the same from one sample to the next, differing only in parameters such as sample identification and file name. Data analysis functions common to all samples, such as baseline adjustments and determination of peak amplitude and spectrum integrals, have also been automated. Conversion of EPR signals to absorbed dose, although not difficult, is not as straightforward because it requires comparisons to previous measurements for calibration dosimeters. This aspect of automation has been deferred. Modification of the EPR spectrometer recorder circuit was also necessary to allow the computer to trigger the acquisition cycle.

\section{Measurement Parameters}

The measurement parameters shown in Table 1 were found to give acceptable performance for the measurement of EPR signals in the RML alanine pellets. Effects of some parameters such as microwave power level and field modulation width were not investigated, but may provide ways of extending the measurement range of the system.

\section{Typical EPR Spectrum}

Figure 3 shows a typical EPR spectrum for irradiated polycrystalline alanine. This curve

Table 1. EPR Measurement Parameters

\begin{tabular}{||l|l|}
\hline Microwave Frequency & $9.347 \mathrm{GHz}$ \\
\hline Magnet Center Field & $332.5 \mathrm{mT}$ \\
\hline Magnet Field Sweep Width & $\pm 10 \mathrm{mT}$ \\
\hline Field Modulation & $100 \mathrm{Khz}$ \\
\hline Field Modulation Width & $0.5 \mathrm{mT}$ \\
\hline Receiver Gain & Variable, 1-1000 \\
\hline Time Constant & $0.03 \mathrm{sec}$ \\
\hline Sweep Time & $1 \mathrm{~min}$ \\
\hline Microwave Power & $0.8 \mathrm{~mW}$ \\
\hline
\end{tabular}
is the first derivative of the resonance absorption spectrum and is output directly by the EPR spectrometer. There are no measurable contributions to the spectrum from the pellet binder materials. Both the double integral of the EPR spectrum (total absorbance) and the amplitude of the primary peak in the differential spectrum 
are proportional to the number of free radicals produced in the alanine. Either value may be used as a measure of absorbed dose.

\section{Gamma Response Curve Characteristics}

The gamma response curve is determined by ${ }^{60} \mathrm{Co}$ irradiations of alanine pellets to known absorbed doses in the GIF [3] at Sandia National Laboratories. Irradiations are done at several levels of absorbed dose per decade from 10 to $10^{5} \mathrm{~Gy}$, with four pellets used at each level. Following the irradiations, the EPR spectrum for each pellet is recorded, using the automated measurement techniques previously described. In all cases, a single EPR scan for each pellet is used.

Response data are normalized to absorbed dose, receiver gain, field modulation width and square root of the microwave power level. Gamma response data are shown in Table 2 for a microwave power level of $0.8 \mathrm{~mW}$, at field modulation widths of $0.5 \mathrm{mT}$ and $0.05 \mathrm{mT}$. Data in Table 2 are the averages of four pellets at each dose point. The same data are scaled and shown in Figure 4 (peak-to-peak) and Figure 5 (integral). The figures also include data for a power level of 0.01 $\mathrm{mW}$. As can be seen from the data, peak-to-peak data are considerably better than integral data at low dose (high gain), both in the linearity of the curve and in the uniformity of response among the four pellets. At high absorbed doses, however, peak-to-peak data suffers from saturation effects that are not as prominent in the integral data. In fact, valid peak-to-peak data are not obtainable for doses above about $1.5 \times 10^{4} \mathrm{~Gy}$ with the measurement parameters given in Table 1 . Additional decreases in the system sensitivity can be accomplished either by decreasing the field modulation width or by decreasing the microwave power level. Either change results in worsening of the signal-to-noise ratio for both peak-to-peak and integral data and significantly affects the data at low absorbed doses. This is clearly illustrated in Figure 6, which shows an EPR spec-

Table 2. Normalized EPR Response for FMW of $0.5 \mathrm{mT}$ and $0.05 \mathrm{mT}$

\begin{tabular}{|c|c|c|c|c|c|c|c|c|c|c|}
\hline \multirow{3}{*}{$\begin{array}{c}\text { Absorbed } \\
\text { Dose (Gy) }\end{array}$} & \multicolumn{5}{|c|}{ Field Modulation Width $=0.5 \mathrm{mT}$} & \multicolumn{5}{|c|}{ Field Modulation Width $=0.05 \mathrm{mT}$} \\
\hline & \multirow{2}{*}{$\begin{array}{c}\text { Receiver } \\
\text { Gain }\end{array}$} & \multicolumn{2}{|c|}{ Peak-to-Peak } & \multicolumn{2}{|c|}{ Integral } & \multirow{2}{*}{$\begin{array}{c}\text { Receiver } \\
\text { Gain }\end{array}$} & \multicolumn{2}{|c|}{ Peak-to-Peak } & \multicolumn{2}{|c|}{ Integral } \\
\hline & & Response & qSD & Response & \%SD & & Response & $\%$ SD & Response & $\%$ SD \\
\hline 10 & 100 & $6.457 \mathrm{E}-1$ & 2.64 & $5.618 \mathrm{E}+4$ & 17.71 & 1000 & $1.074 \mathrm{E}+0$ & 5.56 & $4.599 \mathrm{E}+4$ & 19.03 \\
\hline 20 & 100 & $6.465 \mathrm{E}-1$ & 2.19 & $5.134 \mathrm{E}+4$ & 21.11 & 1000 & $9.622 \mathrm{E}-1$ & 2.13 & $6.656 \mathrm{E}+4$ & 5.80 \\
\hline 40 & 100 & $6.402 \mathrm{E}-1$ & 1.17 & $5.185 E+4$ & 3.05 & 1000 & $8.842 \mathrm{E}-1$ & 0.43 & $5.878 \mathrm{E}+4$ & 9.21 \\
\hline 100 & 100 & $6.341 \mathrm{E}-1$ & 0.45 & $5.367 \mathrm{E}+4$ & 0.73 & 1000 & 8.744E-1 & 1.25 & $6.284 \mathrm{E}+4$ & 4.13 \\
\hline 200 & 10 & $6.445 \mathrm{E}-1$ & 0.73 & $5.315 E+4$ & 2.28 & 100 & 8.647E-1 & 1.10 & $6.204 E+4$ & 1.68 \\
\hline 400 & 10 & $6.437 \mathrm{E}-1$ & 0.18 & $5.269 \mathrm{E}+4$ & 0.94 & 100 & 8.567E-1 & 0.86 & $6.158 \mathrm{E}+4$ & 0.38 \\
\hline 1000 & 10 & 6.132E-1 & 0.59 & $5.040 \mathrm{E}+4$ & 0.38 & 100 & $7.664 \mathrm{E}-1$ & 0.52 & $5.845 E+4$ & 0.44 \\
\hline 2000 & 1 & $6.339 \mathrm{E}-1$ & 0.29 & $5.125 E+4$ & 0.55 & 10 & $8.368 \mathrm{E}-1$ & 0.49 & $5.930 \mathrm{E}+4$ & 0.88 \\
\hline 4000 & 1 & $6.260 \mathrm{E}-1$ & 0.83 & $5.082 E+4$ & 1.60 & 10 & $8.184 \mathrm{E}-1$ & 0.33 & $5.826 \mathrm{E}+4$ & 1.07 \\
\hline 10000 & 1 & $5.822 \mathrm{E}-1$ & 0.40 & $4.824 \mathrm{E}+4$ & 0.27 & 10 & $7.167 \mathrm{E}-1$ & 0.89 & $5.505 E+4$ & 0.43 \\
\hline 20000 & 1 & $4.578 \mathrm{E}-1$ & 0.00 & $4.445 \mathrm{E}+4$ & 0.77 & 1 & $6.985 \mathrm{E}-1$ & 1.11 & $5.191 E+4$ & 2.08 \\
\hline 40000 & 1 & $\cdots$ & $\cdots$ & $3.507 E+4$ & 0.76 & 1 & $5.805 \mathrm{E}-1$ & 0.46 & $4.477 \mathrm{E}+4$ & 0.85 \\
\hline 70000 & $\cdots$ & $\cdots$ & $\cdots$ & $\cdots$ & $\cdots$ & 1 & $4.582 \mathrm{E}-1$ & 0.47 & $3.739 \mathrm{E}+4$ & 0.47 \\
\hline 100000 & $\cdots$ &.-- & $\cdots$ & $\ldots$ & $\cdots$ & 1 & $3.771 \mathrm{E}-1$ & 0.74 & $3.193 \mathrm{E}+4$ & 1.63 \\
\hline
\end{tabular}


trum using a field modulation width of $0.05 \mathrm{mT}$ for an absorbed dose of $10 \mathrm{~Gy}$. Integral data become quite unstable because even small variations in E.PR spectrum baseline contribute to the integral. Although peak-to-peak data are not affected by small variations in baseline, instrumentation noise contributes directly to the peak-to-peak value and results in overestimation of the EPR response at low signal-to-noise ratios. However, peak-to-peak data at absorbed doses greater than $40 \mathrm{kGy}$ show less saturation effects and therefore become usable. These effects are seen in Figures 4 and 5, which show data for field modulation width of 0.05 and for microwave power level of $0.01 \mathrm{~mW}$. For the purposes of this work, data are taken at a microwave power of $0.8 \mathrm{~mW}$ and a field modulation width of $0.5 \mathrm{mT}$. For measurements at high ah sorbed doses, the field modulation width is changed rather than microwave power level. The use of integral data appears to offer no advantage over peak-to-peak data in this region.

Figures 4 and 5 show discontinuities in the data that are well outside the standard deviation with which alanine dosimeters can be read. These discontinuities coincide with changes in system gain and are believed to be the result of system nonlinearities or changes in measurement parameters. They do not affect the results of the current work, but will impact efforts to automate calculations of absorbed dose from EPR response data.

\section{Photon Energy Dependence}

In order to verify the energy response of the alanine dosimeters for photon irradiations, calculations and measurements of absorbed dose were performed for several known photon environments. These included the GIF ${ }^{60} \mathrm{Co}$ facility, the HERMES-III bremsstrahlung X-ray facility [3] operating at endpoint energies of 9 and $18 \mathrm{MeV}$, and the SPHINX bremsstrahlung X-ray facility operating at an endpoint energy of $2.5 \mathrm{MeV}$. Alanine pellets and TLDs were enclosed in Lucite equilibrators as previously described. The thickness of the Lucite surrounding the dosimeters is 6 $\mathrm{mm}$ for the GIF and SPHINX irradiations, and $32 \mathrm{~mm}$ for both the $18-\mathrm{MeV}$ and the $9-\mathrm{MeV}$ HERMES-III irradiations. These thicknesses were chosen to ensure electron equilibrium for the alanine dosimeters in the respective radiation fields. Measured absorbed doses range from approximately 5 Gy to $5000 \mathrm{~Gy}$, depending on the capabilities of the photon sources. Calculations include fully-coupled electron-photon transport and were done with the CEPXS/ONELD discrete-ordinates code [7] using a one-dimensional model of the respective dosimeter packets. Figure 7 shows the energy-dependent photon kermas for alanine and $\mathrm{CaF}_{2}: \mathrm{Mn} \mathrm{TLD}$, derived from the energy-transfer cross sections from Biggs and Lighthill [9]. Figure 8 shows the assumed spectra for the several environments used in this study.

Comparisons between alanine dosimeters and the traditional $\mathrm{CaF}_{2}: \mathrm{Mn}$ TLDs are shown in Table 3, where calculated and measured ratios of absorbed dose are given for the alanine pellets to the $\mathrm{CaF}_{2}: \mathrm{Mn}$ TLDs in their respective equilibrators. Estimated uncertainties in the measured ratios, based on uncertainties in the dose measurements and scatter in multiple measurements for a single

Table 3. Ratios of Absorbed Dose for Photons environment, are on the order of \pm 10 -

\begin{tabular}{||l||c|c|}
\hline \multirow{2}{*}{\multicolumn{1}{|c||}{ Environment }} & \multicolumn{2}{c|}{$\begin{array}{c}\text { Ratio, Dose(Alanine) to } \\
\text { Dose(TLD) }\end{array}$} \\
\cline { 2 - 3 } & Calculated & Measured \\
\hline \hline GIF $\left({ }^{60} \mathrm{Co}\right)$ & 1.08 & 1.12 \\
\hline HERMES-III $(18 \mathrm{MeV})$ & 0.90 & 1.21 \\
\hline HERMES-III $(9 \mathrm{MeV})$ & 0.96 & 1.38 \\
\hline SPHINX $(2.5 \mathrm{MeV})$ & 0.80 & 0.96 \\
\hline
\end{tabular}


$12 \%$. Estimated uncertainties in the calculated dose ratios are on the order of $\pm 8-10 \%$, and are due primarily to uncertainties in the assumed photon spectra. Good agreement between calculated and measured values for the GIF is expected because this facility is used for calibration of both the TLDs and the alanine dosimeters. The difference between calculated and measured dose ratios for the GIF facility is consistent with the precision with which the measurements can be made. The differences between the calculated and measured dose ratios for the bremsstrahlung facilities exceed that which might be expected from the uncertainty estimates. The reasons for this are still being investigated, but might include inadequate modeling of source electrons, unidentified modeling errors in the calculation of the photon spectra at low energies, or inadequate equilibration for the TLD, as discussed earlier.

\section{Neutron Energy Dependence}

Calculations and measurements of absorbed dose were made for several mixed neutron/photon environments, including the central cavity of the SPR-III, the central cavity of the ACRR, and the ACRR FREC fitted with a cadmium and polyethylene liner. This selection of facilities provides a wide range of neutron-to-gamma ratios. Because the alanine sensitivity to neutrons is significantly larger than that for the $\mathrm{CaF}_{2}: \mathrm{Mn}$ TLDs, there are substantially different ratios of alanine dose to TLD dose for the various environments. The relative effectiveness for neutrons in alanine has been reported in the literature [10]. The neutron response was determined from first principles with track-structure calculations and was in excellent agreement with experimental measurements for a wide range of neutron energies. The energy dependence of the neutron effectiveness in alanine is shown in Figure 9. The relative effectiveness of neutrons in $\mathrm{CaF}_{2}: \mathrm{Mn}$ TLDs is very low. The energy-dependent efficiency can be modeled as the neutron energy (in $\mathrm{MeV}$ ) divided by 100 [11]. For a fission neutron spectrum this results in an efficiency of approximately $3 \%$ of the neutron absorbed dose. Characterization of neutron spectra for the three reactor environments is described in a separate report [12]. Photon spectra were assumed to be that for fission gammas. Energy-dependent neutron kermas for the alanine dosimeters and the TLDs were derived from ENDF/B-VI [13] cross sections processed with NJOY [14], and are shown in Figure 10. The larger neutron kerma for alanine at higher energies is mostly due to the $(n, p)$ reaction in hydrogen. At lower neutron energies, the higher neutron kerma is due to the large cross section for the ${ }^{14} \mathrm{~N}(\mathrm{n}, \gamma)^{15} \mathrm{~N}$ reaction. The absorbed dose in the dosimeter attributable to neutrons is calculated by weighting the energy-dependent kerma with the relative effectiveness for the neutrons, and folding that with the neutron spectrum. The total dose is the sum of the photon and effective neutron absorbed doses.

Table 4 shows the calculated and measured ratios of absorbed dose for the alanine pellets to the $\mathrm{CaF}_{2}: \mathrm{Mn}$ TLDs for the three neutron environments. The table also shows calculated neutron-togamma ratios for those environments. Estimated uncertainties in the measured dose ratios are on the order of $\pm 10-12 \%$. Estimated uncertainties in the calculated
Table 4. Ratios of Absorbed Dose for Neutrons

\begin{tabular}{||l||c|c|c||}
\hline \multirow{2}{*}{ Environment } & \multirow{2}{*}{$\begin{array}{c}\text { Neutron } \\
\text { to Gamma } \\
\text { Ratic }\end{array}$} & \multicolumn{2}{|c|}{$\begin{array}{r}\text { Ratio, Dose(Alanine) to } \\
\text { Dose(TLD) }\end{array}$} \\
\cline { 2 - 4 } & Calculated & Measured \\
\hline SPR-III Cavity & 1.61 & 4.02 & 4.28 \\
\hline ACRR Cavity & 0.73 & 1.82 & 2.13 \\
\hline FREC, Cd/Poly & 0.18 & 1.26 & 1.42 \\
\hline
\end{tabular}


dose ratios are on the order of $\pm 10 \%$. As expected, the ratio of alanine dose to TLD dose decreases as the neutron-to-gamma ratio decreases because of the higher neutron response in alanine. The calculated dose ratios have the same general behavior as the measured dose ratios. The calculated ratios all assume a prompt-fission-gamma spectrum, which would be representative of the SPR-III cavity. For this environment, the calculated dose ratio is about $6 \%$ lower than the measured ratio. The ACRR pool-type reactor actually has a significantly softer, degraded, photon component. The difference between calculated and measured ratios for the ACRR cavity is about $15 \%$. The FREC Cd/Poly environment has a harder, higher-energy photon component that results from $(n, \gamma)$ reactions in cadmium by low-energy neutrons. The difference between calculated and measured ratios for the FREC is about $11 \%$. Detailed Monte Carlo calculations are being performed to provide a better quantitative model of the actual photon spectra in these environments and to provide a better foundation for the assigned neutronto-gamma ratios.

\section{Alternate Materials}

Teflon has been investigated briefly as an alternative to alanine that might be more appropriate for testing of silicon devices, due to its lower hydrogen content and resultant low neutron sensitivity. Initial results with Teflon are encouraging. Figure 11 shows an EPR signal from a Teflon pellet irradiated in the GIF to an absorbed dose of approximately 600 Gy. The spectrum consists of only a single resonance.

Preparation of the pellets is relative simple, consisting of pressing with a tableting press a pellet from a pre-weighed amount of Teflon, which can be obtained in powdered form or in the form of tape. Although a relatively simple procedure, manufacture of a Teflon pellet is time consuming because the Teflon is not easily weighed. Obtaining uniform pellets is therefore difficult. In addition, the pellets cannot be hardened by annealing, and are therefore somewhat prone to peeling or chipping. It is therefore unlikely that sufficiently large numbers of pellets can be made in this way to make them useful for routine dosimetry. Other methods of making the pellets may be possitle, such as slicing from an extruded rod, providing that rods having relatively tight dimensional tolerances can be obtained, and providing that no spurious contributions to the EPR signal arise from the extruding and cutting operations.

Published literature [15] has also suggested the possible use of thermoluminescence materials with EPR spectrometry for measurement of absorbed dose. This would provide a dual-technique readout of a dosimeter. Attempts to use $\mathrm{CaF}_{2}: \mathrm{Mn}$ TLDs did not result in measurable EPR signals, although other phosphors might be useable.

\section{Conclusions and Recommendations}

A system has been successfully developed for the use of EPR spectroscopy with L- $\alpha$-alanine for high-precision absorbed-dose measurements. The system has been sufficiently automated to allow a systematic optimization of measurement parameters. A relatively small effort will be required to extend the application of this system to routine measurements in photon environments.

The calculated and measured alanine-to-TLD dose ratios were in acceptable agreement for the neutron environments, but not for the photon environments. However, the calculations for the 
neutron environments depend on the modelling of photon sensitivities. Using the measured alanine-to-TLD dose ratios for the photon environments rather than the calculated ratios might improve further the agreement between calculated and measured ratios for the neutron environments. The issue of photon spectrum sensitivity is unresolved and work is continuing.

One of the initial objectives of this research was to determine if this technique could be used for silicon-equivalent dose measurements (e.g., testing of electronics) in mixed neutron/photon environments. Because of the very large neutron contribution to the measured dose and the correspondingly large uncertainties in the corrections that would be needed, the use of alanine is not recommended for high-precision silicon-equivalent dose measurements. However, this technique is suitable for applications requiring tissue-equivalent dose measurements. Fielding TLDs and alanine together in mixed fields would also be quite useful in establishing neutron-togamma ratios and in characterizing additional photon environments.

Investigation of alternate materials for silicon-dose-equivalent measurements in mixed fields should be pursued further. The ratio of neutron kerma to photon kerma for Teflon is much closer than alanine's to that of silicon, and initial results with Teflon in photon environments has been encouraging. However, the energy-dependence of the neutron relative efficiency has not yet been established for Teflon.

The alanine dosimeter system has been used on a limited basis in support of other experimental programs, including gamma field mapping at GIF, validation of measurements made with alternate dosimetry methods, and measurement of tissue-equivalent doses at SPR.

\section{References}

[1] W.L. McLaughlin, A.W. Boyd, K.H. Chadwick, J.C. McDonald and A. Miller, Dosimetry for Radiation Processing, Taylor \& Francis, London, p. 175, 1989.

[2] "Standard Practice for the Application of Thermoluminescence-Dosimetry (TLD) Systems for Determining Absorbed Dose in Radiation-Hardness Testing of Electronic Devices," E668(93), Annual Book of Standards, Vol. 12.02, American Society for Testing and Materials, 1993.

[3] Radiation Facilities, L.M. Choate, T.R. Schmidt and G.A. Zawadzkas, Eds., SAND891299, Sandia National Laboratories, December 1989.

[4] P.D. Morse II, EPRWare User Manual, V2.41, Scientific Software Services, Bloomington IL, 1990.

[5] Technical Procedure: Preparing AlanineiPolyethylene Pellets, RML-EPR-01, Radiation Metrology Laboratory, Sandia National Laboratories, 1993.

[6] A. Dutreix and A. Bridier, "Dosimetry for External Beams of Photon and Electron Radiation," in The Dosimetry of Ionizing Radiation, Vol. I, K. Kase, B Bjärngard and F. Attix, Eds., Academic Press, Inc., Orlando, p. 163, 1985. 
[7] L.J. Lorence, J.E. Morel and G.D. Valdez, Results Guide to CEPXS/ONELD: A OneDimensional Coupled Electron-Photon Discrete Ordinates Code Package, Version 1.0, SAND89-2211, Sandia National Laboratories, July 1990.

[8] P.J. Griffin, D.W. Vehar and J. VanDenburg, Characterization of SNL Photon Dosimeters, SAND93-1421, Sandia National Laboratories, March 1994.

[9] F. Biggs and R. Lighthill, Analytical Approximations for X-Ray Cross Sections III, SAND87-0070, Sandia National Laboratories, August 1988, Updated 1990.

[10] M.P.R. Waligórski, G. Danialy, K.S. Loh and R. Katz, "The Response of the Alanine Detector After Charged-particle and Neutron Irradiations," in Applied Radiation and Isotopes, Vol. 40, No. 10-12, pp. 923-933, 1989.

[11] F.H. Attix, Introduction to Radiological Physics and Radiation Dosimetry, John Wiley \& Sons, p. 493, 1986.

[12] P.J. Griffin, J.G. Kelly and D.W. Vehar, Updated Neutron Spectrum Characterization of SNL Baseline Reactor Environments, SAND93-2554, Sandia National Laboratories, December 1993.

[13] ENDF-201, ENDF/B-VI Summary Documentation, P.F. Rose, Ed., BNL-NCS-1741, Brookhaven National Laboratory, October 1991.

[14] R.E. MacFarlane, D.W. Muir and R.M. Boicourt, The NJOY Nuclear Data Processing System, Vol. 1: User's Manual, report LA-9303-M, ENDF-324, May 1982. Code available as PSR-171 from the Oak Ridge Radiation Shielding Information Center.

[15] E. Bortolin, P. Fattibene, C. Furetta and S. Onori, "ESR of $\mathrm{Mg}_{2} \mathrm{SiO}_{4}$ :Tb TL Phosphors," in Applied Radiation and Isotopes, Vol. 44, No. 1/2, pp. 327-330, 1993. 


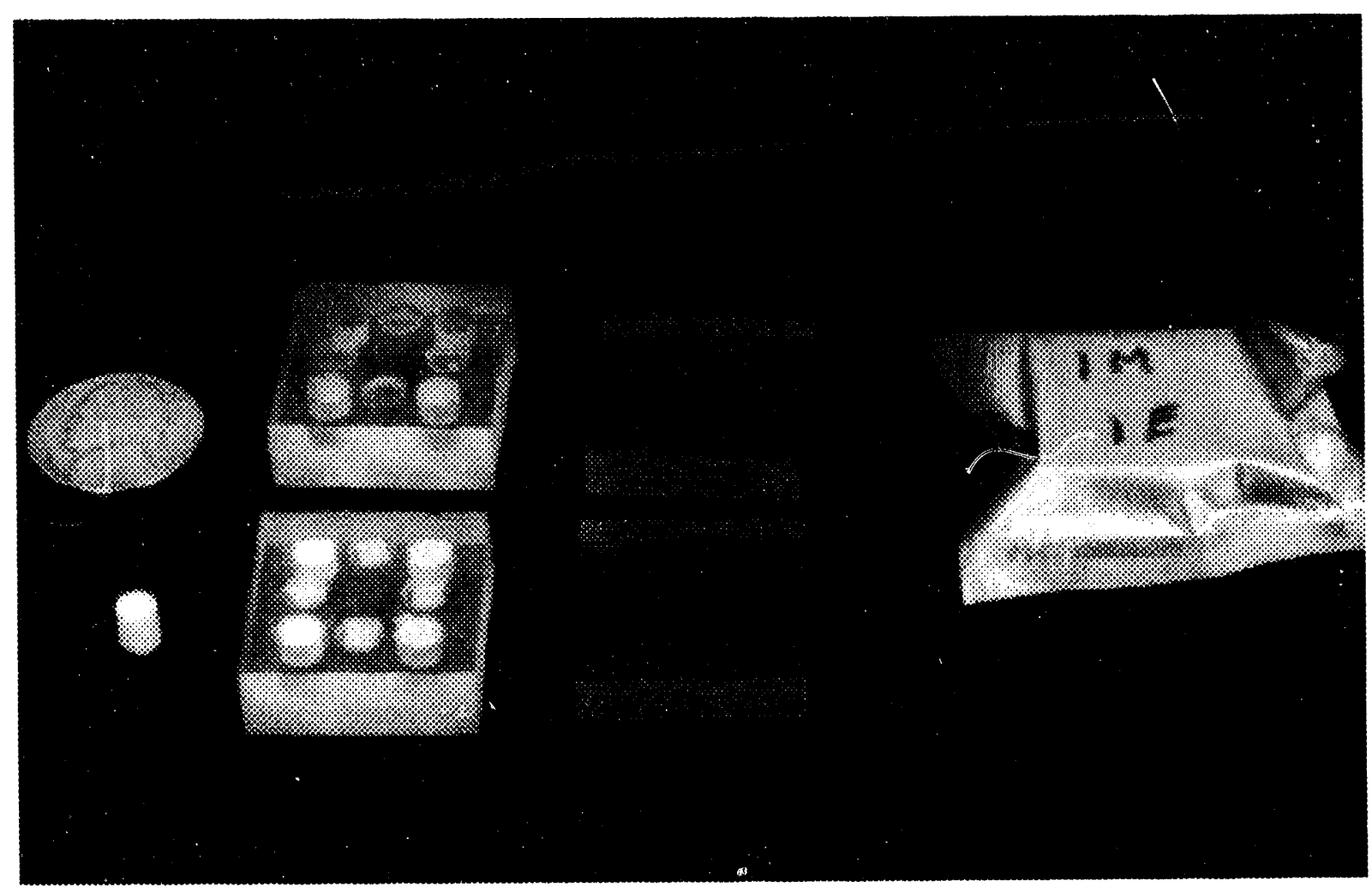

Figure 1. Alanine Dosimeter Packets

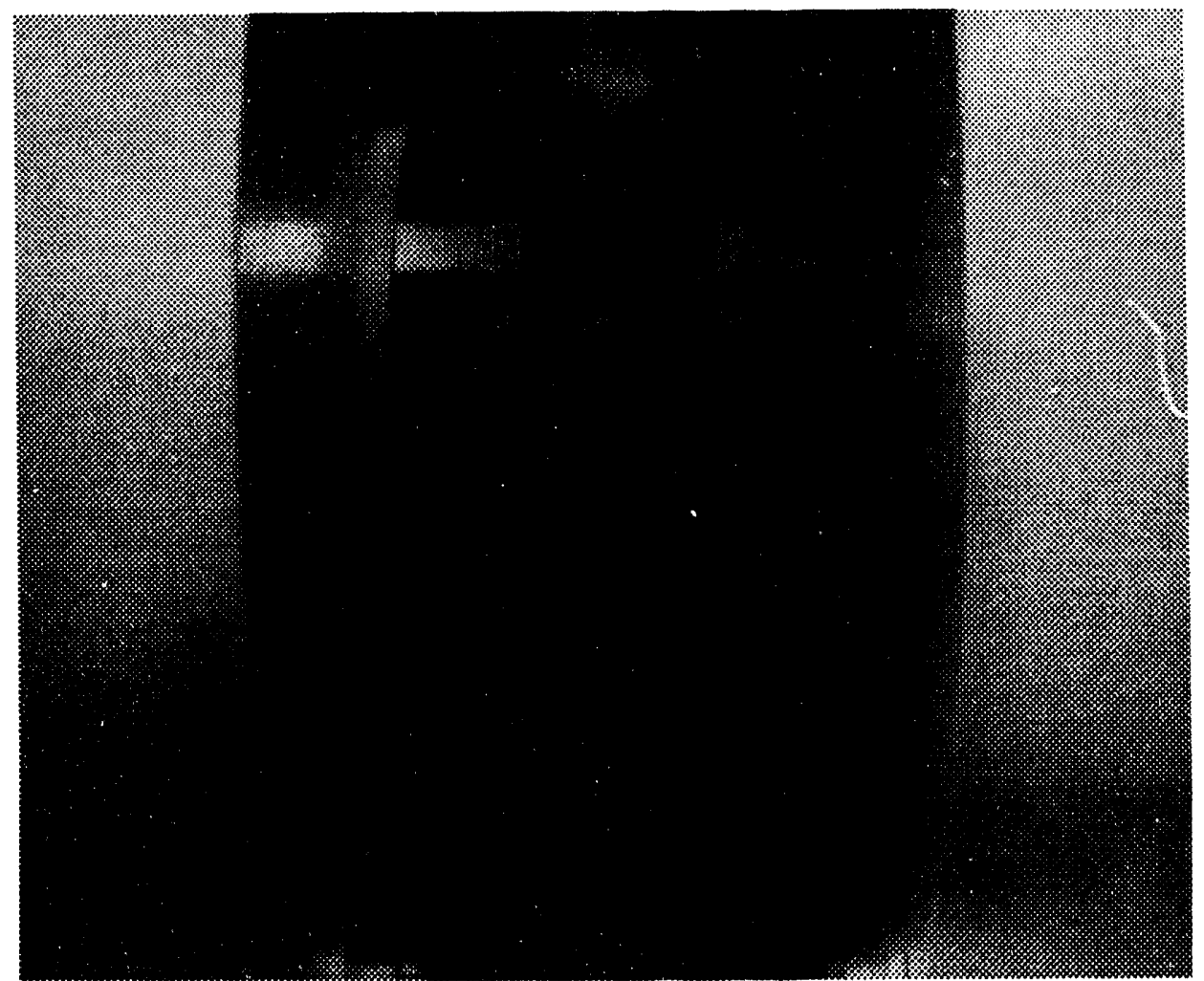

Figure 2. Microwave Cavity and Sample-Changer Mechanism

$-11-$ 


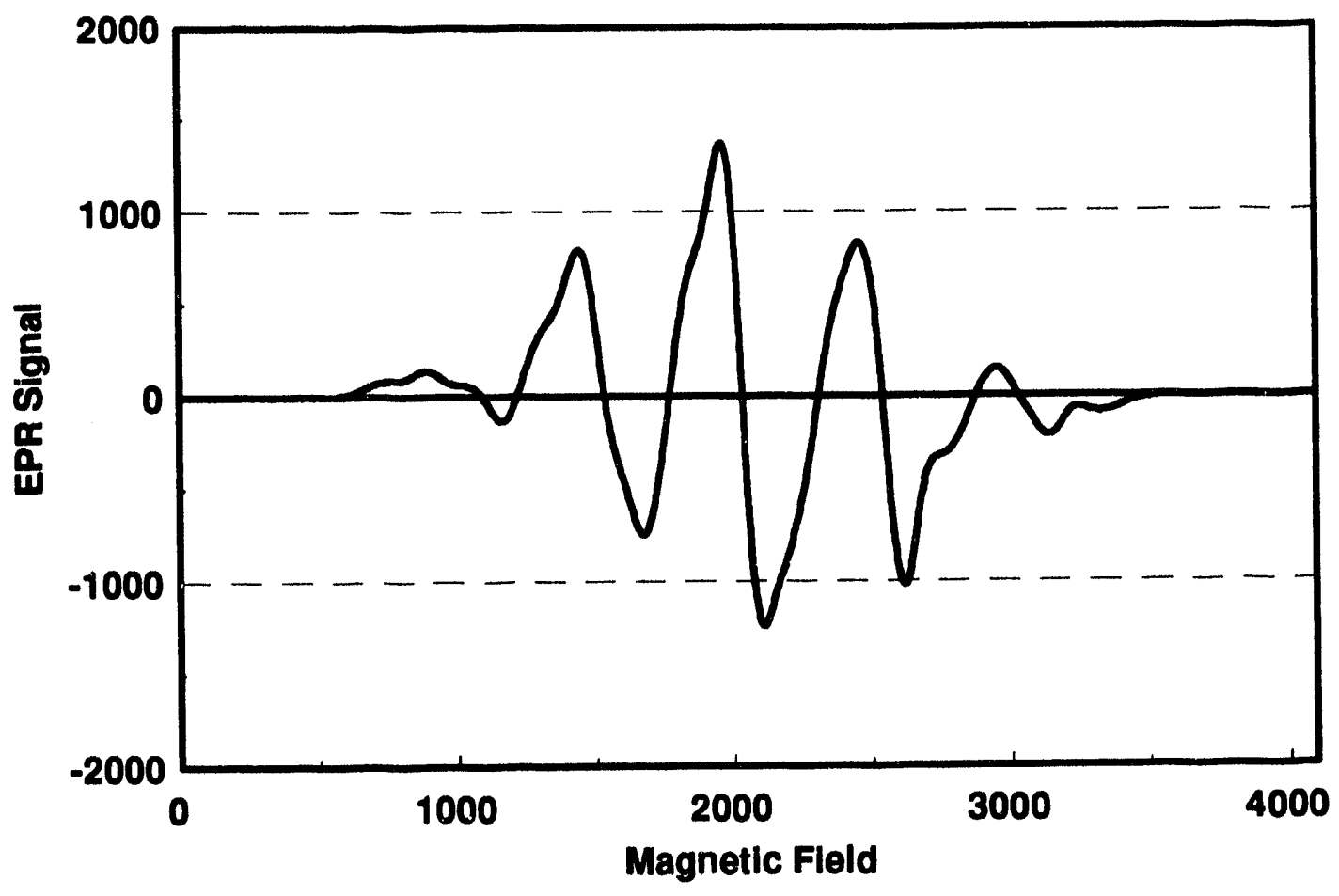

Figure 3. Alanine EPR Spectrum, Gain $=1, \mathrm{FMW}=0.5 \mathrm{mT}$, Dose $=10 \mathrm{kGy}$

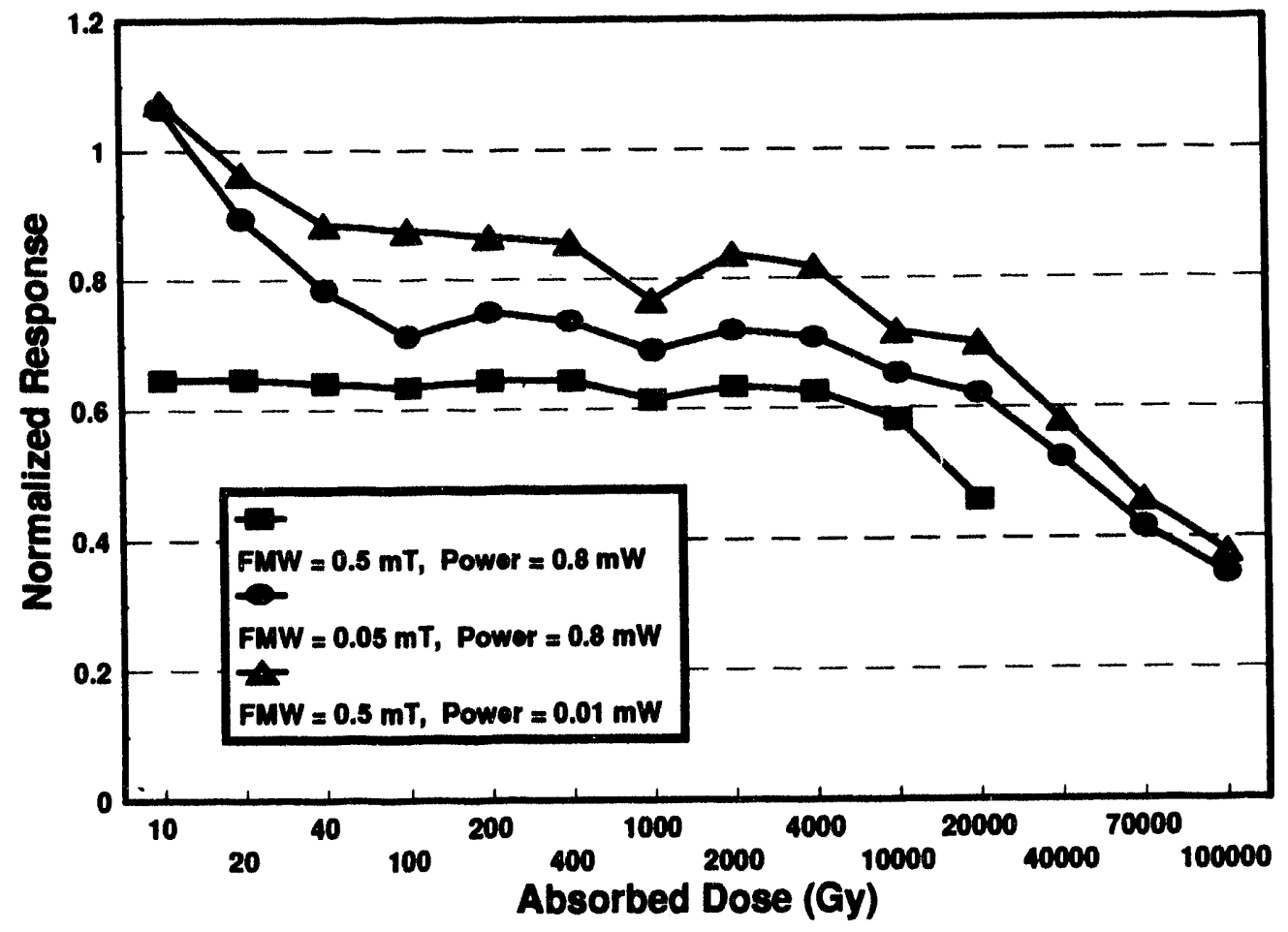

Figure 4. Normalized EPR Response, Peak-to-Peak Method 


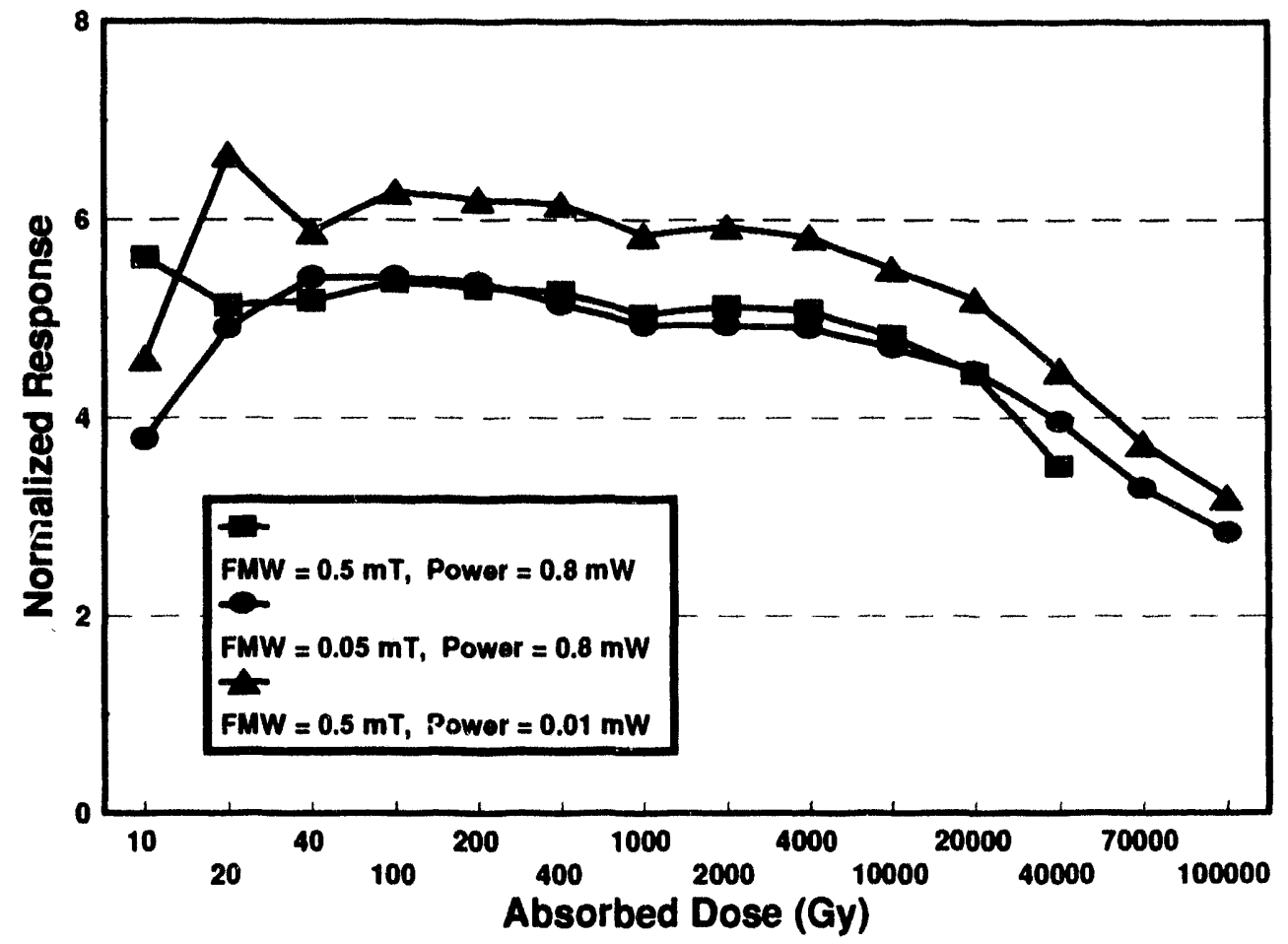

Figure 5. Normalized EPR Response, Integral Method

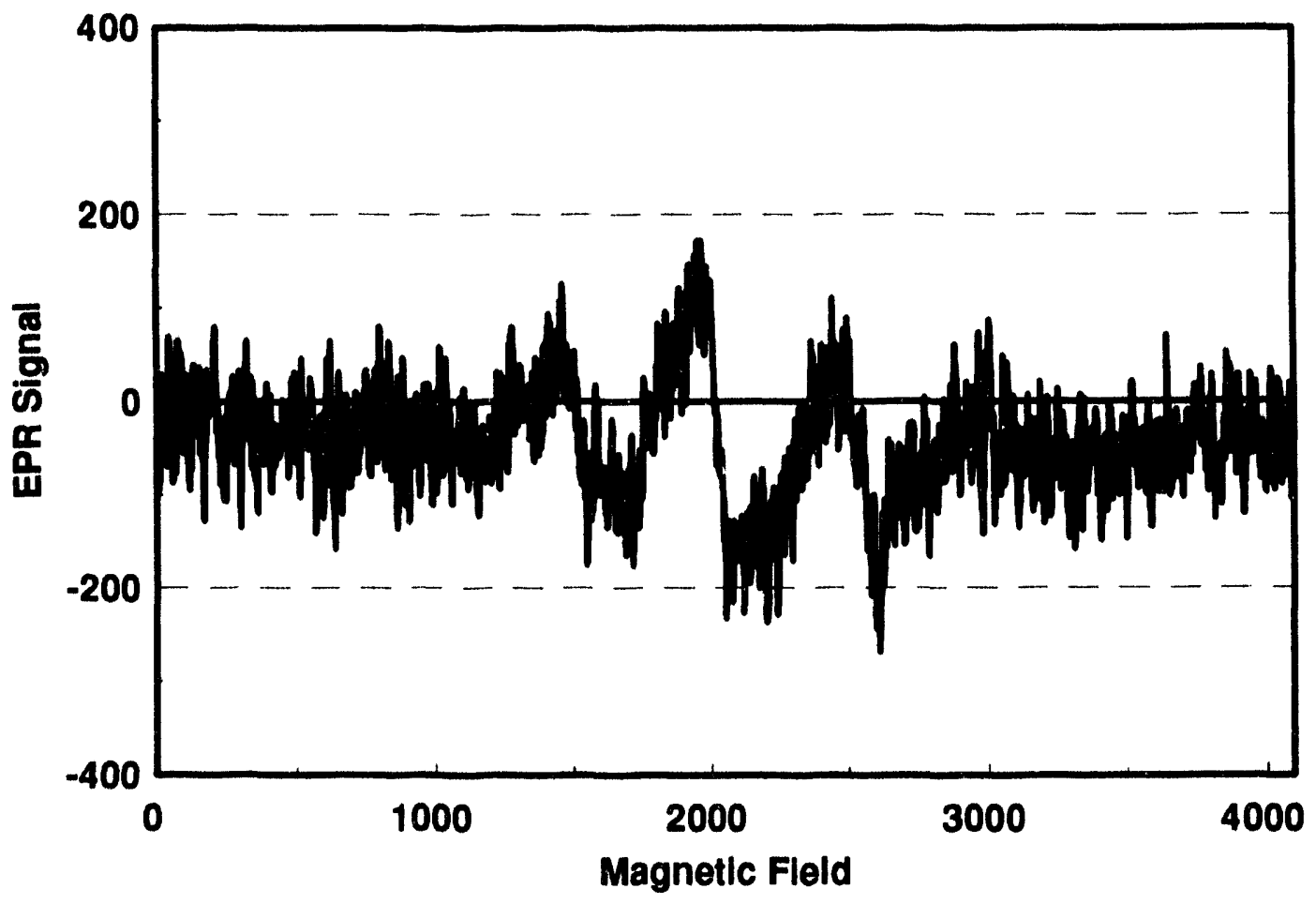

Figure 6. Alanine EPR Spectrum, Gain $=1000, \mathrm{FMW}=0.05 \mathrm{mT}$, Dose $=10 \mathrm{~Gy}$ 


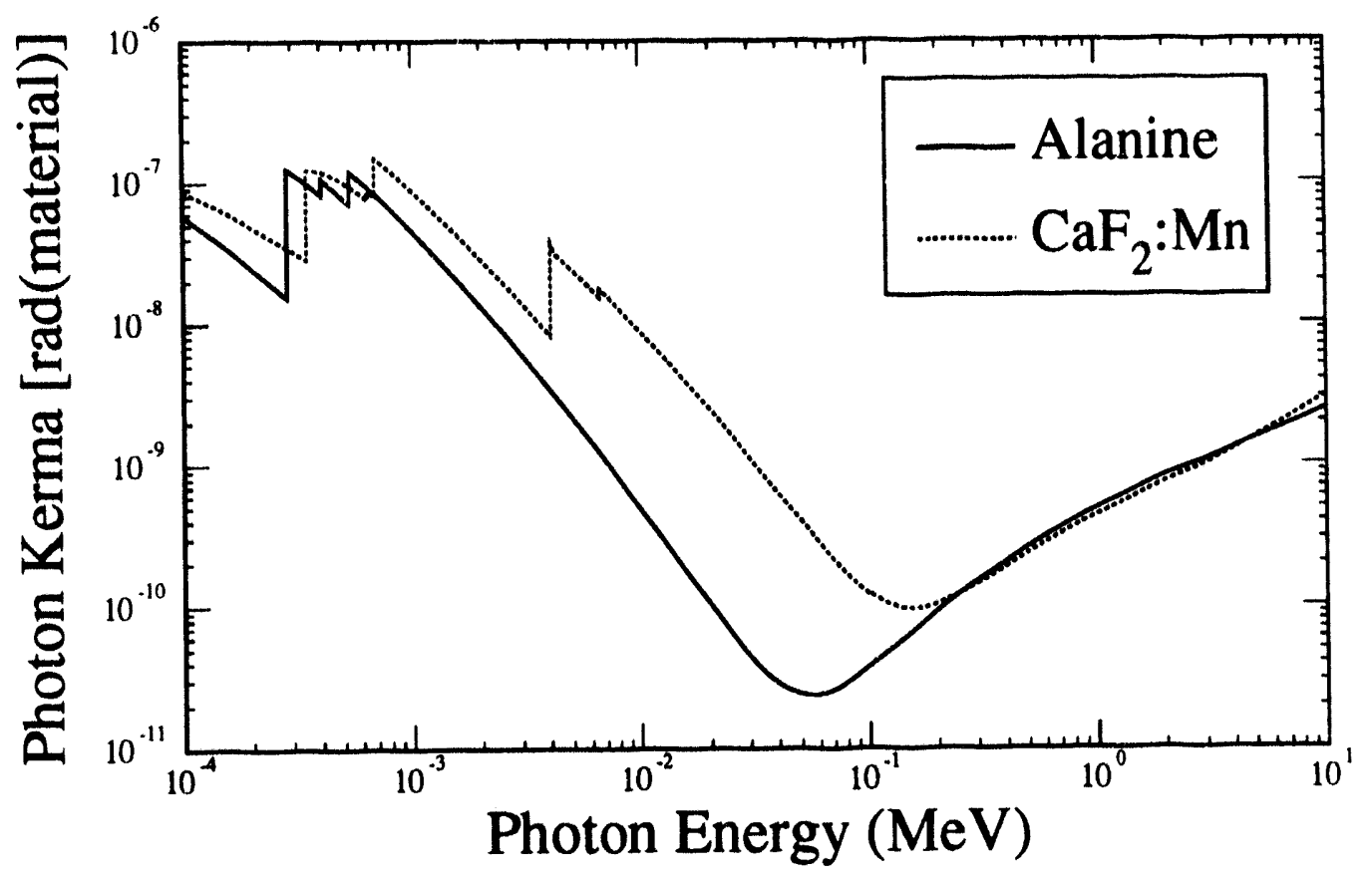

Figure 7. Energy-Dependent Photon Kerma

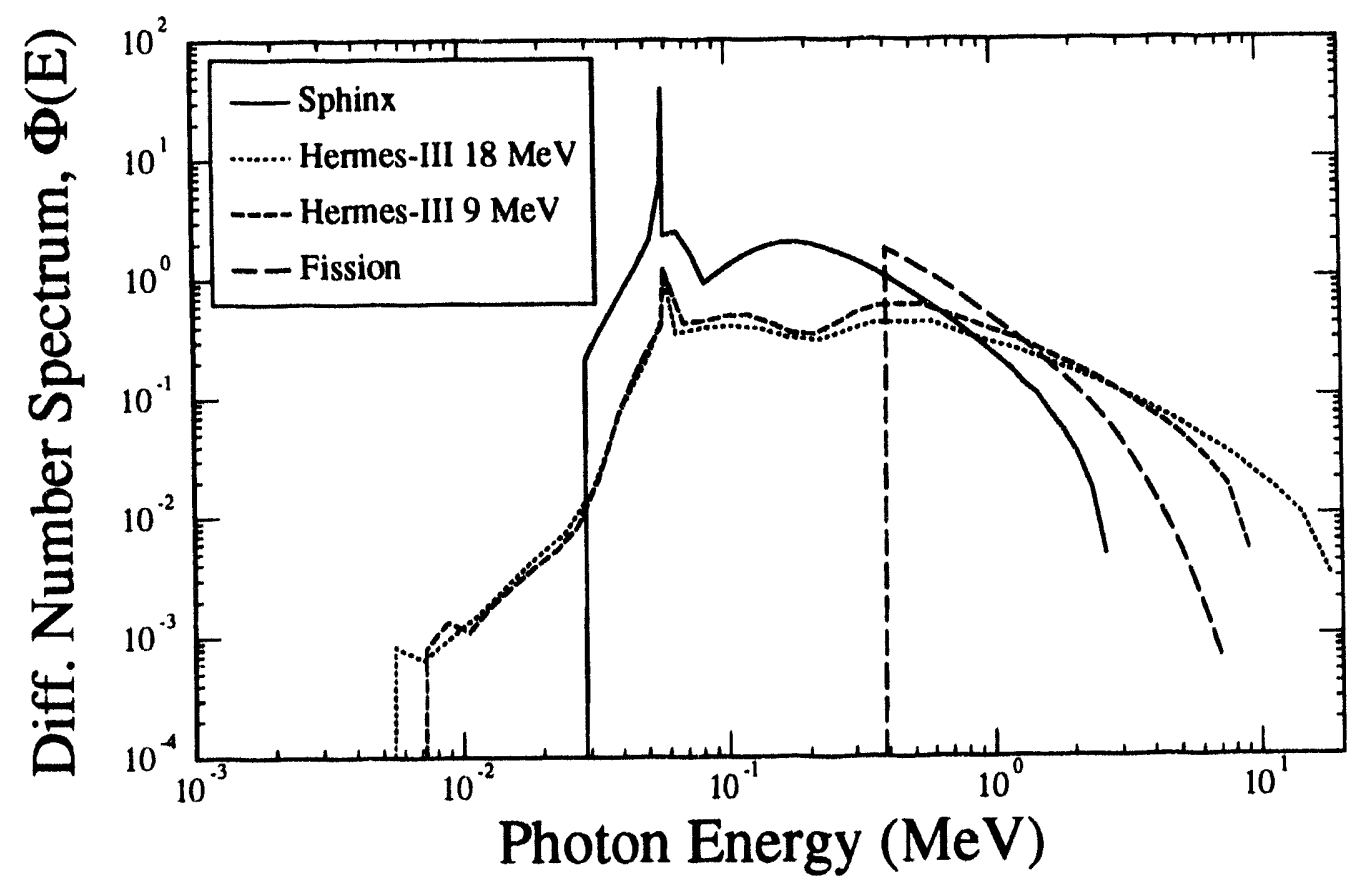

Figure 8. Photon Spectra 


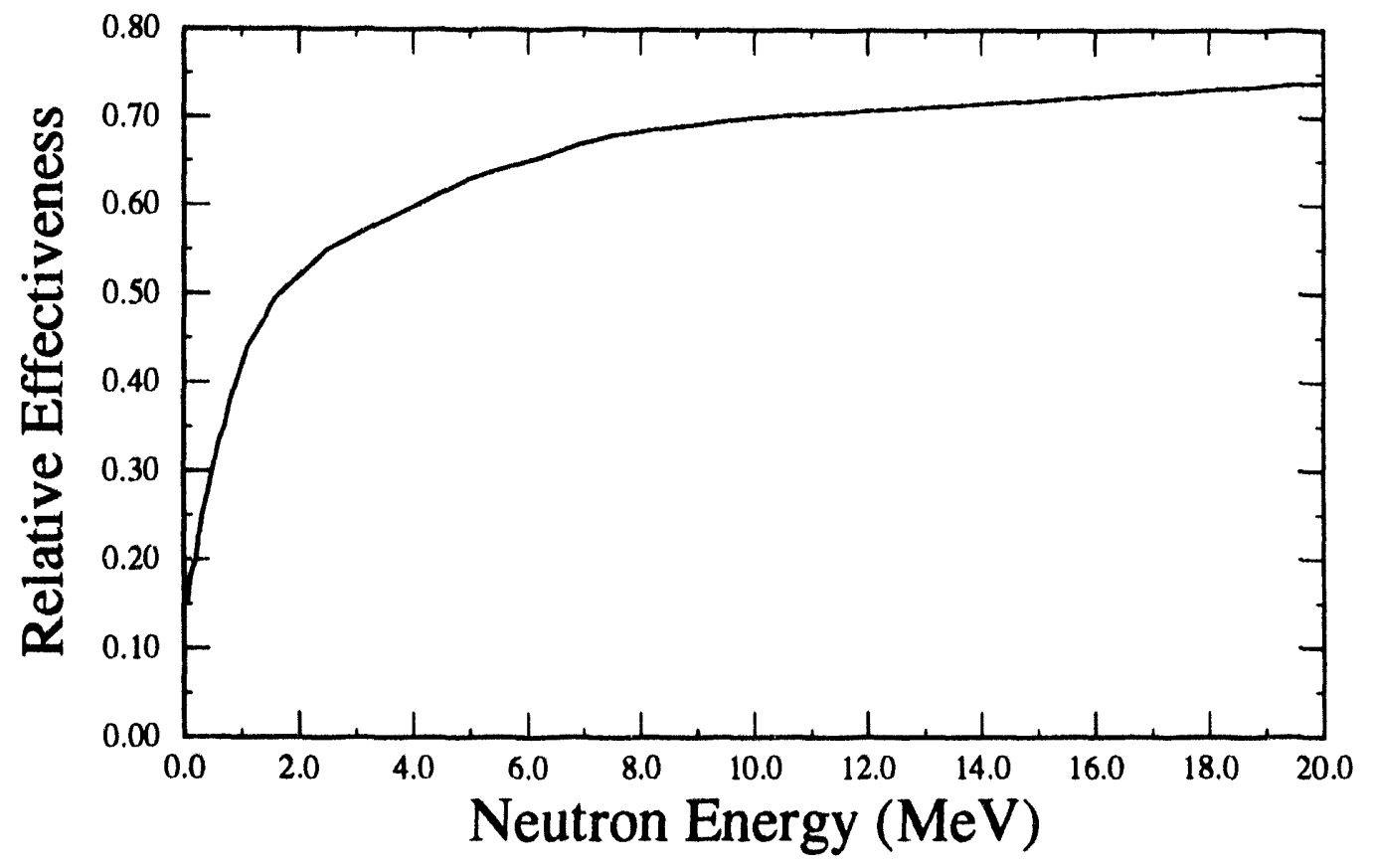

Figure 9. Energy Dependence of Neutron Effectiveness

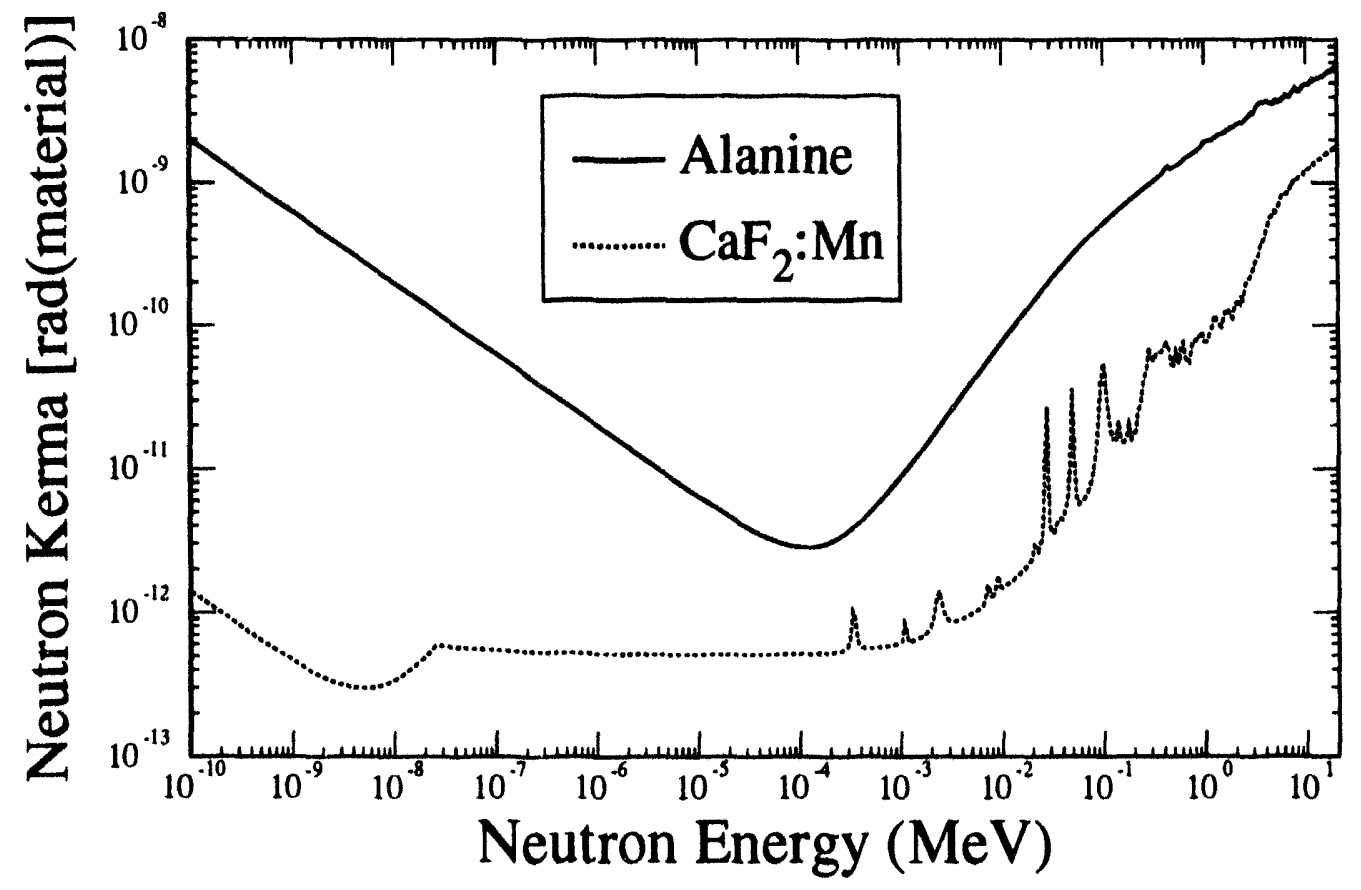

Figure 10. Energy-Dependent Neutron Kerma 


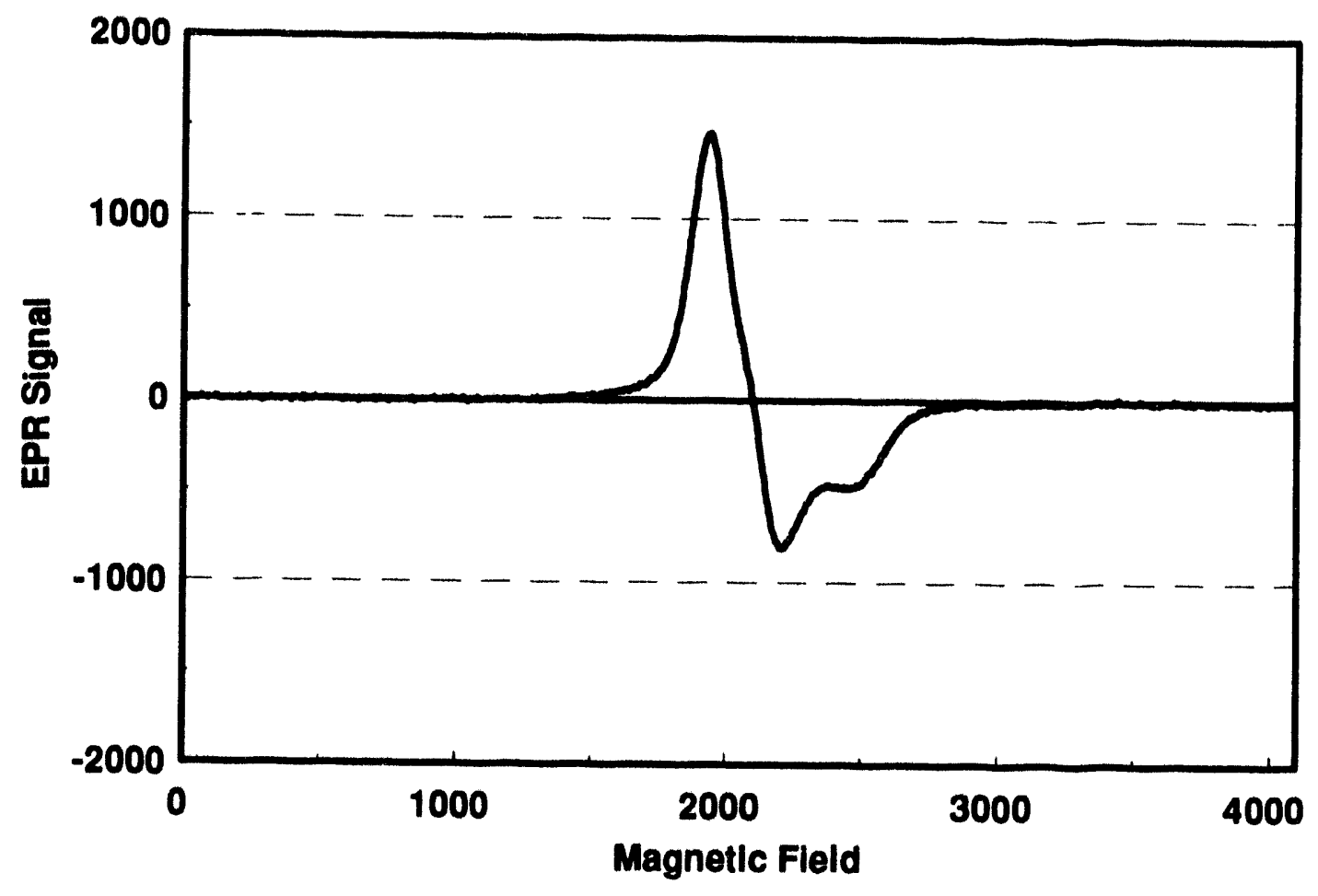

Figure 11. Teflon EPR Spectrum, Gain=100, FMW $=0.5 \mathrm{mT}$, Dose $600 \mathrm{~Gy}$ 


\section{DISTRIBUTION:}

$\begin{array}{lrl}1 & \text { MS 320 } & \text { LDRD Office, 1011 } \\ 1 & 1143 & \text { J.K. Rice, 6500 } \\ 1 & 1146 & \text { T.F. Luera, 6500B } \\ 1 & 1145 & \text { P.S. Pickard, 6514 } \\ 20 & 1145 & \text { P.J. Griffin, 6514 } \\ 1 & 1142 & \text { J.W. Bryson, 6521 } \\ 20 & 1142 & \text { D.W. Vehar, 6521 } \\ 1 & 9018 & \text { Central Technical Files, 8523-2 } \\ 5 & 0899 & \text { Technical Library, 7141 } \\ 1 & 0619 & \text { Technical Publications, 7151 } \\ 10 & 1119 & \text { Document Processing, 7613-2 } \\ & & \text { For DOE/OSTI }\end{array}$



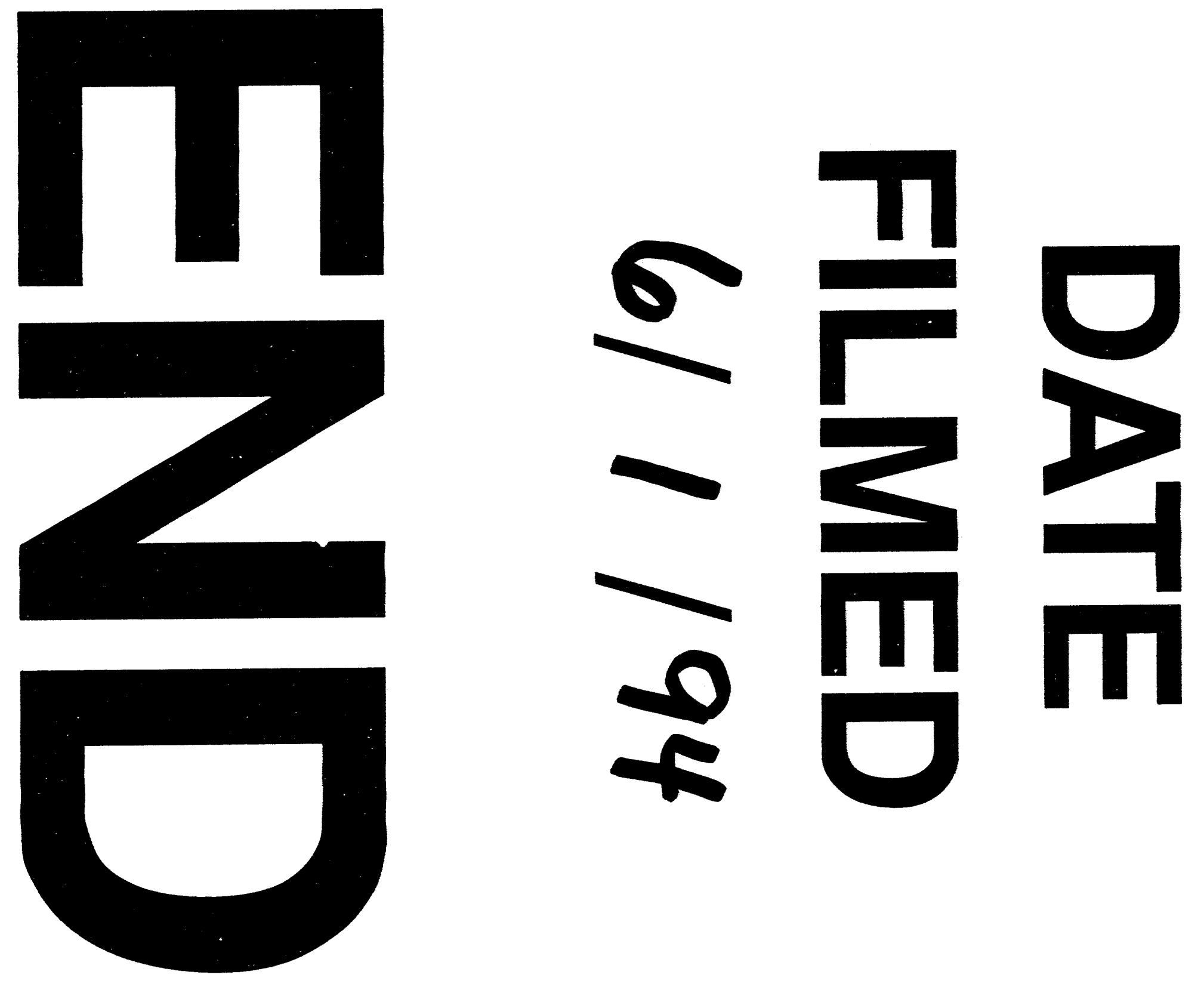
